\title{
Pelaksanaan program Edmodo di sekolah dasar
}

\author{
Feni Febryani Zaman ${ }^{1}$ *, Cepi Safruddin Abdul Jabar ${ }^{2}$ \\ ${ }^{1}$ Sekolah Dasar Negeri 079 Bandung. \\ J1. Pasirkoja No. 37, Nyengseret, Astanaanyar, Bandung, Jawa Barat 40242, Indonesia. \\ ${ }^{2}$ Fakultas Ilmu Pendidikan, Universitas Negeri Yogyakarta. \\ Jl. Colombo No. 1, Karang Malang, Depok, Sleman, Daerah Istimewa Yogyakarta 55281, Indonesia. \\ fenifebryanizaman@gmail.com \\ * Corresponding Author
}

\section{ARTICLE INFO}

\section{Article History}

Received:

10 March 2020;

Revised:

29 July 2020;

Accepted:

4 August 2020

\section{Keywords}

Program Edmodo;

Manajemen program

Edmodo;

E-learning;

Edmodo program;

Edmodo program

management

\begin{abstract}
Penelitian ini bertujuan untuk mendeskripsikan pelaksanaan program Edmodo di Sekolah Dasar Percobaan Negeri (SDPN) Sabang dan Sekolah Dasar Kristen (SDK) 5 BPK Penabur kota Bandung. Pendekatan penelitian yang digunakan adalah kuali-tatif, desain studi kasus. Subyek penelitian dengan purposive sampling yaitu ambassador, manajer Edmodo Amerika Serikat, guru, siswa, orang tua, kepala SDPN Sabang dan SDK 5 BPK Penabur, pengawas, Kepala Dinas Pendidikan kota Bandung dan staf program sarana dan prasarana. Teknik pengumpulan data yang digunakan adalah wawancara, observasi, dan dokumen. Pengujian keabsahan data adalah teknik triangulasi, member-check, dan audit eksternal oleh dosen pembimbing. Teknik analisis data menggunakan model Creswell. Hasil penelitian mengungkap pelaksanaan program Edmodo yaitu mengkaji dimensi siswa, guru, dan stakeholder yang terlibat dalam pelaksanaan program Edmodo. Permasalahan dalam pelaksanaan Edmodo adalah hambatan mindset dan niat, signal, sarana dan prasarana Edmdo, dan limitasi grup.
\end{abstract}

This research aims to describe the implementation of the Edmodo program at Sekolah Dasar Percobaan Negeri (SDPN) Sabang and Sekolah Dasar Kristen (SDK) 5 BPK Penabur Bandung. The research approach was qualitative, case study design. Research subjects with purposive sampling consisted of Ambassador, Edmodo's United States manager, teachers, students, parents, head of SDPN Sabang and SDK 5 BPK Penabur Bandung, supervisor, head of Bandung Education Office, and staff of infrastructures. The techniques of collecting data were interviews, observation, and documents. The validity testing of data was triangulation, member-checking, and external audits by the lecturer. The analysis data used was qualitative analysis data from Creswell. The results of this research were the implementation of the Edmodo program was to examine the dimensions of students, teachers, and stakeholders involved in the implementation of the Edmodo program. The problem in the implementation was the barrier of mindset and intention, signal, infrastructure, and group limitation.

This is an open access article under the $\underline{\mathrm{CC}-\mathrm{BY}-\mathrm{SA}}$ license.

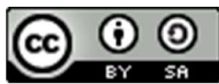

How to cite:

Zaman, F. F., \& Jabar, C. S. A. (2020). Pelaksanaan program Edmodo di sekolah dasar. Jurnal Akuntabilitas

Manajemen Pendidikan, 8(1), 96-107. doi: https://doi.org/10.21831/jamp.v8i1.30589 


\section{PENDAHULUAN}

E-learning menurut Clark dan Mayer $(2011$, p. 8) adalah instruksi yang disampaikan dalam perangkat digital seperti komputer atau smartphone yang dimaksudkan untuk mendukung pembelajaran. Darmawan (2014, p. 86), menjelaskan bahwa e-learning merupakan suatu bentuk implementasi teknologi yang ditujukan untuk membantu proses pembelajaran yang dikemas dalam bentuk elektronik atau digital dan pelaksanaannya membutuhkan sarana komputer berbasis website dalam sebuah situs internet. Program pembelajaran digital Edmodo adalah sebuah media pembelajaran yang berbasis e-learning, dimana guru dan siswa dapat saling terhubung, berdiskusi, dan berbagi materi melalui sebuah jaringan internet. Hal ini didukung oleh penelitian sebelumnya yang berjudul Edmodo is a free and secure educational learning network used to provide a simple way for teachers to create and manage an online classroom community as well as enables students to connect and work with their classmetes teachers anywhere and anytime oleh Balasubramanian, Jaykumar, dan Fukey (2014).

Di dalam fitur Edmodo, terdapat 3 jenis pengguna yaitu Student, Teacher, dan Parent. Ketiga pengguna itu dapat megakses Edmodo di manapun yang mereka kehendaki selama terdapat komputer atau smartphone yang dilengkapi atau tersedia koneksi internet. Siswa dan guru dapat mengaksesnya di sekolah dengan memanfaatkan komputer dan koneksi internet ketika berada di laboraturium komputer atau dengan memanfaatkan laptop sendiri yang terkoneksi internet dengan modem maupun wifi. Pengguna parent, orang tua siswa dapat mengakses Edmodo dari rumah, sehingga mereka dapat memantau serta memonitoring perkembangan anak mereka dalam proses pembelajaran mengunakan aplikasi Edmodo. Sekolah dasar di kota Bandung sudah menggunakan kurikulum 2013 secara keseluruhan. Oleh karena itu, setiap siswa diharapkan mampu memiliki 3 kompetensi Abad-21 yang harus dicapai dari kurikulum 2013 tersebut yaitu kemampuan belajar dan berinovasi, literasi digital, dan kecakapan hidup. Sarana yang tepat untuk dijadikan literasi digital bagi siswa sekolah dasar di kota Bandung yang aman adalah dengan pemanfaatan program Edmodo.

Siswa sekolah dasar di kota Bandung banyak yang sudah menggunakan smartphone (Rahma \& Jonyanis, 2015) sebagai alat komunikasi, bermain games, dan sudah mulai mengenal internet sebelum Edmodo ada di kota Bandung, sehingga Edmodo dapat mengalihkan fungsi smartphone tersebut bukan hanya sebagai alat komunikasi saja, tetapi smartphone dijadikan sebuah sarana pembelajaran dengan memanfaatkan kemajuan teknologi, komunikasi, dan informasi melalui aplikasi Edmodo. Pentingnya pemanfaatan teknologi dan informasi bagi pendidikan termaktub dalam Peraturan Menteri Pendidikan dan Kebudayaan Republik Indonesia Nomor 65 Tahun 2013 tentang Standar Proses Pendidikan Dasar dan Menengah yang menjelaskan temtamg Standar Kompetensi Lulusan (SKL) dan Standar Isi (SI), prinsip pembelajaran yang digunakan pada poin 13 adalah pemanfaatan teknologi informasi dan komunikasi untuk meningkatkan efisiensi dan efektivitas pembelajaran.

Berdasarkan permasalahan tersebut, penelitian ini dimaksudkan untuk mengungkap pelaksanaan program Edmodo di Sekolah Dasar Percobaan Negeri (SDPN) Sabang yang beralamat di Jl. Sabang No. 2, Cihapit, Bandung Wetan, Kota Bandung, Jawa Barat dan Sekolah Dasar Kristen (SDK) 5 BPK Penabur yang beralamat di Jl. Guntur No. 34, Malabar, Lengkong, Kota Bandung Jawa Barat agar pembelajaran digital dapat terlaksana dengan baik di kedua sekolah tersebut. Laptop dan smartphone siswa pun dapat dimanfaatkan sebagai media pembelajaran.

\section{METODE}

Pendekatan dalam penelitian ini adalah pendekatan kualitatif dengan desain studi kasus. Studi kasus merupakan suatu penelitian yang dilakukan terhadap suatu situasi untuk mengkontribusikan pengetahuan berupa program, kegiatan, peristiwa, fenomena individu, kelompok, organisasi, dan sosial (Yin, 2009, p. 4). Studi kasus dalam penelitian ini mengarahkan peneliti untuk menghimpun data, mengambil makna, memperoleh pemahaman, dan mempertahankan karakteristik yang unik dari pelaksanaan program Edmodo di Sekolah Dasar Percobaan Negeri (SDPN) Sabang dan Sekolah Dasar Kristen (SDK) 5 BPK Penabur kota Bandung. Karakteristik unik tersebut tidak dimiliki oleh Sekolah Dasar lain di kota Bandung. Penelitian ini dilakukan pada bulan Desember 
2016 sampai dengan Juni 2017. Namun sebelumnya peneliti mengambil data wawancara dengan Manajer Edmodo dari Amerika Serikat ketika 24 April 2016, yang kebetulan Manajer Edmodo dari Amerika Serikat tersebut melakukan kunjungan ke kota Bandung.

Subyek dalam penelitian ini berjumlah 19 (sembilan belas) orang informan yang terdiri atas ambassador Edmodo, manajer Edmodo dari Amerika, guru, siswa, orang tua, dan kepala sekolah Dasar Percobaan Negeri (SDPN) Sabang dan Sekolah Dasar Kristen (SDK) 5 BPK Penabur kota Bandung, pengawas sekolah dasar kota Bandung, kepala Dinas Pendidikan kota Bandung, dan staf program bagian sarana dan prasarana Dinas Pendidikan kota Bandung. Pemilihan informan dalam penelitian ini diperoleh dengan teknik purposive sampling yakni berdasarkan pertimbangan tertentu dari peneliti karena subyek penelitian yang peneliti pilih dianggap paling tahu tentang pelaksanaan program Edmodo di SDPN Sabang dan SDK 5 BPK Penabur kota Bandung. Teknik pengumpulan data melalui wawancara, observasi, dan analisis dokumen.

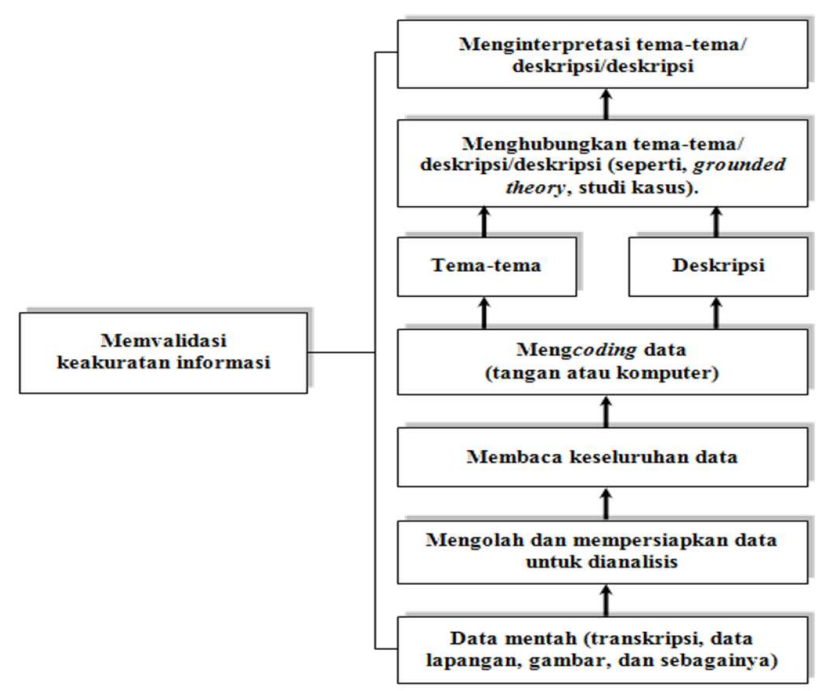

Gambar 1. Proses Analisis Data Penelitian Kualitatif Model Creswell

Analisis data dalam penelitian ini menggunakan model 6 (enam) langkah Creswell (2014, p. 196), yaitu: 1.) Mengolah dan mempersiapkan data; 2.) Membaca keseluruhan data; 3.) Menganalisis lebih detail dengan melakukan proses coding data; 4.) Menerapkan coding untuk mendeskripsikan hasil temuan; 5.) Menyajikan dan mendeskripsikan tema-tema dengan pendekatan naratif; dan 6.) Melakukan interpretasi atau memaknai data. Keenam komponen ini saling berinteraksi dan membentuk suatu siklus analisis data yang dapat dilihat pada Gambar 1.

Uji keabsahan data dalam penelitian kualitatif meliputi uji credibility, transferability, dependability, dan confirmability (Sugiyono, 2015, p. 366). Namun yang peneliti lakukan hanya credibility, transferability, dan confirmability. Uji kredibilitas (credibility) atau validasi internal merupakan salah satu ukuran tentang kebenaran data yang dikumpulkan dan menggambarkan konsep peneliti dengan konsep yang diperoleh dari informan atau narasumber. Pada tahapan ini dilakukan kegiatan: 1.) Triangulasi, kegiatan yang peneliti lakukan sebagai koreksi kebenaran data dengan cara membandingkan antara data yang diperoleh dari triangulasi sumber (dari 19 orang informan yang berbeda) dan triangulasi teknik (wawancara, observasi, dan dokumen); 2.) Member checks, kegiatan ini dilakukan untuk menyimpulkan secara bersama dengan setiap narasumber setelah peneliti melakukan wawancara, dalam praktiknya peneliti hanya melakukan member check kepada kepala sekolah SDPN Sabang dan SDK 5 BPK Penabur kota Bandung.

Kegiatan transferability disebut juga dengan kegiatan validasi eksternal. Hasil penelitian ini dimungkinkan dapat diterapkan di tempat lain seperti di sekolah dasar lain yang ada di kota Bandung. Konfirmability, kegiatan pada tahap ini sama dengan uji objektivitas hasil penelitian, berarti menguji hasil penelitian, dikaitkan dengan proses yang dilakukan. Bila hasil penelitian merupakan fungsi dari 
proses peneitian yang dilakukan, maka penelitian tersebut memenuhi standar konfirmability. Uji konfirmability yang peneliti lakukan dengan cara pemeriksaan ulang sekaligus pengecekan untuk memberikan keyakinan bahwa hal-hal yang dilaporkan dapat dipercaya dan sesuai dengan situasi nyata di lapangan.

\section{HASIL DAN PEMBAHASAN}

Hasil

\section{Dimensi Siswa}

Di SDPN Sabang pelaksanaan Edmodo rutin dilaksanakan satu minggu sekali. Adapun untuk harinya berbeda-beda sesuai dengan kebijakan wali kelas masing-masing, selama dua jam pelajaran. Selain Edmodo, pembelajaran secara digital class di kelas 5 SDPN Sabang juga mempelajari animasi drawing Sparkol, blog, edugame, dan pembuatan komik secara digital. Saat belajar Edmodo siswa merasa senang, karena mendapat tambahan ilmu dan dapat berinteraksi dengan teman dari luar sekolah bahkan luar kota. Pelaksanaan Edmodo di SDK 5 BPK Penabur belum terprogram secara rutin, yang rutin baru Ulangan Dalam Jaringan (UDJ) saja, karena keterbatasan jumlah komputer di laboraturium komputer sekolah. Siswa yang melaksanakan Edmodo baru kelas tinggi. Siswa merespon sangat baik adanya Edmodo ini, respon baik siswa tersebut terbukti dengan adanya polling kepuasan siswa pada salah satu fitur Edmodo.

\section{Situasi/Kondisi Pembelajaran}

Situasi atau kondisi pembelajaran Edmodo di SDPN Sabang dan SDK 5 BPK Penabur kota Bandung dengan didukung oleh dokumen dan observasi adalah siswa sangat antusias dan merasa senang belajar dengan menggunakan Edmodo, pembelajaran lebih interaktif, memudahkan guru dalam proses kegiatan pembelajaran, dan dalam evaluasi pembelajaran kondisi siswa cukup tertib, karena ketika mengerjakan soal evaluasi di Edmodo disajikan dengan lebih menarik dan interaktif.

Guru

Guru yang melaksanakan Edmodo di SDPN Sabang adalah guru kelas 4, 5, dan 6. Guruguru mempersiapkan dengan matang bahan ajar maupun soal yang akan diupload ke Edmodo melalui KKG maupun mandiri. Berdasarkan hasil pengamatan ketika observasi dalam pelaksanaan Edmodo, guru hanya mengarahkan, menjelaskan apa yang harus dilakukan siswa, dan mengawasi siswa selama pelaksanaan Edmodo. Selebihnya siswa yang berperan aktif dalam pelaksanaan Edmodo tersebut. Terdapat salah satu guru SDPN Sabang kota Bandung yang sangat luar biasa dalam program kelas digital Edmodo, guru tersebut berhasil menjadi motivator dan melatih guru-guru lain maupun guru dari luar kota terkait program Edmodo ini. Guru di SDK 5 BPK Penabur yang sudah bisa mengguankan Edmodo adalah hampir semua guru termasuk guru kelas 1. Tetapi yang melaksanakan Edmodo itu sendiri baru beberapa guru kelas 3 dan semua guru kelas 4, 5, 6 .

\section{Stakeholder}

Pihak yang terlibat dalam pelaksanaan Edmodo adalah guru, siswa, kepala sekolah, dan orang tua siswa. Peran guru menjadi lebih utama dalam pembangunan nilai keunggulan setiap anak bangsa. Tuntutan masyarakat terhadap layanan pendidikan yang bermutu semakin mendorong guru untuk kreatif dalam menciptakan layanan pembelajaran yang inovatif, berpusat pada siswa, dilandasi nilai-nilai religi dan kearifan lokal. Nilai-nilai religi dan kearifan lokal harus menjadi "ruh" dan pendukungekuatan (support power) bagi guru untuk lebih memerankan kedudukan dan fungsi profesionalnya, serta meningkatkan layanan pendidikan yang berkualitas, terjangkau, dan berkeadilan. Selain guru dan siswa, kepala sekolah memiliki perannya dalam pelaksanaan Edmodo, kepala sekolah menjadi pembimbing dan penanggung jawab pelaksanaan Edmodo di sekolah. Adapun peran orang tua dalam pelaksanaan Edmodo di SDPN Sabang dan SDK 5 BPK Penabur kota Bandung adalah orang tua sangat mendukung dalam hal penyediaan fasilitas Edmodo berupa laptop, smartphone, atau tablet beserta kuota internetnya. Orang tua siswa ikut memantau perkembangan belajar putra putrinya melalui aplikasi parent pada Edmodo, dab sebagai pengawas, orang tua siswa 
mengarahkan putra-putrinya pada konten positif dalam mengakses internet dengan bekerja sama dengan sekolah, pemberi support pengadaan fasilitas Edmodo di rumah, sebagai pengontrol kinerja sekolah, kualitas sekolah, dan memantau perkembangan belajar putra-putrinya melalui aplikasi parent pada Edmodo.

\section{Kendala dalam Pelaksanaan Program Edmodo}

Kendala dalam pelaksanaan Edmodo di SDPN Sabang dan SDK 5 BPK Penabur adalah hambatan awal dari orang tua siswa yang mengkhawatirkan putra putrinya dalam memanfaatkan internet, keterbatasan sinyal jaringan internet, sekolah yang belum mempunyai fasilitas laptop sebanyak jumlah siswa keseluruhan yang menggunakan Edmodo, dan anak-anak yang lupa mencharge laptop dari rumah, sehingga lowbat saat digunakan di sekolah. Kendala dari Edmodo diinformasikan kepada sekolah, dan sekolah kemudian mengadakan perbaikan dan kendala tersebut bisa teratasi. Kendala terkini pelaksanaan di tahun ajaran 2016/2017 adalah kapasitas dari grup, kapasitas siswa yang dapat bergabung dalam satu grup tidak bisa melebihi dari 2.000 siswa. Setelah lebih dari 2.000 siswa user admin harus membuatkan grup baru.

Persamaan kendala yang dialami oleh kedua sekolah tersebut yaitu kendala fasilitas sarana dan prasarana dalam memanfaatkan Edmodo sebagai media dalam penyampaian proses kegiatan belajar mengajar. Hanya saja SDPN Sabang kota Bandung dapat mengatasinya dengan cara bekerja sama dengan orang tua siswa dalam pengadaan fasilitas Edmodo tersebut. Pada SDK 5 BPK Penabur, kendala fasilitas Edmodo yaitu dalam hal penyesuaian jadwal penggunaan laboraturium komputer, sehingga guru dan siswa tidak bisa leluasa dalam belajar Edmodo, dan mereka harus bergantian terlebih dahulu dengan kelas lain dalam penggunaan laboraturium komputer sekolah

\section{Cara Mengatasi Kendala Pelaksanaan}

Dinas Pendidikan kota Bandung memantau penyebab kendala yang terjadi di lapangan. Jika kendalanya infrastruktur, Dinas Pendidikan kota Bandung berusaha untuk membantunya, jika kendalanya dari sumber daya guru-gurunya yang kurang, Dinas Pendidikan kota Bandung mengadakan pelatihan secara gratis untuk guru-guru tersebut. Cara mengatasi kendala dalam pelaksanaan Edmodo di SDPN Sabang dan SDK 5 BPK Penabur kota Bandung adalah 1.) Bekerja dengan ikhlas dan tetap semangat dalam melaksanakan program Edmodo; 2.) Menentukan dan menggunakan provider yang tepat di sekolah ketika melaksanakan Edmodo,; 3.) Saling berbagi kuota antar teman atau mengguanakan modem guru ketika pelaksanaan Edmodo; 4.) Antara sekolah dan orang tua siswa bekerja sama dan berkolaborasi dengan baik demi keberhasilan pelaksanaan program Edmodo, terutama dalam penyediaan fasilitas Edmodo; dan 5.) Penyesuaian jadwal dengan kelas lain untuk menggunakan laboraturium komputer. Kendala terkait limitasi peserta grup disampaikan langsung oleh ambassador ke Edmodo Amerika melalui WhatsApp dan video conference dengan langsung menghubungi teknisi dan humas internasional Edmodo.

\section{Kekhawatiran Internet Usia Sekolah Dasar dan Solusinya}

Hasil penelitian mengungkapkan bahwa kekhawatiran internet pada anak usia sekolah dasar tidak dijadikan penghambat untuk lebih maju. Sebagai guru harus bisa mencari cara bagaimana dapat memfilter penggunaan internet melalui pendekatan terhadap siswa dengan memberikan pemahaman yang berhubungan dengan agama dan penggunaan serta pemanfaatan internet secara lebih positif. Selain itu, mengawasi penggunaan dalam pemanfaatan IT kepada anak-anak, jika guru mengambil bahan ajar dari konten youtube, guru akan menyimpan link veideo pembelajaran tersebut ke dalam google drive/kecatatan khusus atau guru membuat video pembelajaran sendiri. Guru harus sering mengingatkan anak, mengarahkan anak, dan melatih anak agar senang pada konten positif. Dinas Pedidikan, pengawas, kepala sekolah, dan guru kota Bandung hanya memberi hal yang positif untuk mengurangi waktu mereka untuk mengakses hal lain. Dinas Pedidikan, pengawas, kepala sekolah, dan guru tidak mempunyai kemampuan untuk mencegah siswa mengakses hal-hal yang dia inginkan, tetapi memberi ruang dan waktu untuk mengakses hal-hal positif. Melalui Edmodo guru-guru dan siswa dapat saling terkoneksi dan tidak perlu menggunakan biaya transportasi yang mahal dalam bertatap muka dan melakukan proses kegiatan pembelajaran. 
Pembahasan

Dimensi Siswa

Siswa yang melaksanakan program Edmodo harus memiliki karakter siswa online. Karakter siswa online dijelaskan oleh Pujiriyanto (2012, p. 193) yaitu: 1.) Memiliki motivasi untuk berafiliasi atau bergabung; 2.) Memahami nilai dari interaksi dan kolaborasi; 3.) Memiliki focus of control yang baik; 4.) Memiliki konsep akademik yang baik; 5.) Pengalaman terlibat dalam pembelajaran yang memerlukan pengarahan diri; dan 6.) Terampil menggunakan teknologi online.

\section{Situasi/Kondisi Pembelajaran}

Situasi atau kondisi pembelajaran Edmodo memperlihatkan antusias siswa dengan merasa senang belajar dan mempermudah guru dalam melaksanakan proses belajar mengajar. Hal ini didukung oleh peneliti sebelumnya Balasubramanian, Jaykumar, dan Fukey (2014, p. 416) dalam hasil penelitiannya menunjukkan bahwa menggabungkan Edmodo dalam proses pembelajaran mendorong keterlibatan siswa dan pembelajaran yang bertanggung jawab saat fitur Edmodo dikerjakan. Hasilnya melalui analisis tersebut mendukung bahwa preferensi siswa untuk menggunakan Edmodo terutama ditujukan untuk sumber daya, dukungan, dan komunikasi seperti forum, diskusi dan juga untuk aktivitas online. Siswa menemukan Edmodo sebagai platform pembelajaran sosial yang bagus dan mudah digunakan yang memungkinkan mereka menikmati tugas di kelas online.

\section{Guru}

Kemajuan yang pesat dalam teknologi membuat perubahan pada proses pengajaran yang dilakukan oleh guru. Sebagaimana sesuai dengan teori Whitehead, Boschee, dan Decker (2013, p. 275) tentang pengajaran di era digital, guru dituntut untuk melakukan perubahan sebagai sekolah era industri menuju sekolah era digital, diantaranya dengan cara: 1.) Memfasilitasi dan menginspirasi belajar dan kreativitas siswa; 2.) Mendesain dan mengembangkan pengalaman dan penilaian belajar era digital; 3.) Bekerja dan belajar dengan model digital; 4.) Mempromosikan dan bertanggungjawab terhadap kewargaan digital; dan 5.) Terlibat dalam pertumbuhan kepemimpinan yang profesional. Kunandar (2007, p. 41) mengungkapkan bahwa untuk menghadapi era globalisasi yang penuh dengan persaingan dan ketidakpastian, dibutuhkan guru yang visioner dan mampu mengelola proses belajar mengajar secara efektif dan inovatif.

\section{Stakeholder}

Pihak-pihak yang terlibat dalam pelaksanaan Edmodo diantaranya adalah guru, siswa, kepala sekolah, dan orang tua siswa. Pihak yang terlibat dalam pelaksanaan Edmodo salah satunya adalah guru. Guru dituntut untuk kreatif dalam menyajikan bahan ajar di Edmodo. Hal ini didukung oleh pendapat Uno dan Mohamad (2013, p. 152) yang menyatakan bahwa guru harus kreatif, karena guru menjadi faktor kunci untuk mengembangkan potensi peserta didik agar menjadi manusia yang beriman dan bertakwa kepada Tuhan Yang Maha Esa, berakhlak mulia, sehat, berilmu, cakap, kreatif, mandiri, serta menjadi warga negara yang demokratis dan bertangung jawab. Begitu pula dengan pendapat Usman (2013) yang mengungkapkan bahwa guru yang profesional adalah orang yang memiliki kemampuan dan keahlian khusus dalam bidang keguruan, sehingga ia mampu mela-kukan tugas dan fungsinya sebagai guru dengan kemampuan yang maksimal.

Pihak selanjutnya yang terlibat dalam pelaksanaan Edmodo adalah siswa. Siswa merupakan pemeran utama dalam pelaksanaan Edmodo. Dalam pelaksanaan Edmodo diperlukan siswa yang kreatif, hal ini senada dengan yang diungkapkan oleh Mulyasa (2015, p. 86) bahwa peserta didik yang kreatif memiliki rasa ingin tahu, suka mencoba, dan senang bermain. Dengan adanya sikap kreatif yang baik dari siswa perlu dilatih untuk memiliki kekuatan memori yang baik, tentunya dalam pembelajaran Edmodo ini. Untuk mendukung pendapat Mulyasa tersebut, Dyches, Carter, dan Prater (2012, p. 7) mengungkapkan bahwa memahami latar belakang keluarga siswa yang adalah dasar untuk mengembangkan hubungan asuhan dengan siswa dan keluarga mereka. Komunikasi akan lebih efektif jika mengetahui audiensi orang tua tertentu yang ingin dijangkau, termasuk demografi keluarga, keluarga yang beragam secara budaya atau bahasa, dan keluarga membesarkan anak-anak dengan berbagai macam bakat. 
Kepala sekolah juga berperan dalam pelaksanaan Edmodo. Seperti yang diungkapkan Whitehead, Boschee, dan Decker (2013, p. 276) bahwa kepala sekolah memainkan peran penting dalam menentukan seberapa baik teknologi yang digunakan di sekolah mereka. Whitehead, Boschee, dan Decker (2013, p. 276) juga menambahkan bahwa National Educational Technology Standards (NETS) dikembangkan untuk administrator, terutama kepala sekolah oleh the intenational society for Technology in Education, yang terdiri dari: 1.) Kepemimpinan visioner; 2.) Budaya belajar era digital; 3.) Unggul dalam praktek profesional; 4.) Perbaikan sistemik; dan 5.) Kewarganegaraan digital.

Pihak yang mendukung terlaksananya Edmodo dengan baik selanjutnya adalah orang tua siswa. Seperti yang diungkapkan oleh Whitehead, Boschee, dan Decker (2013, p. 329) bahwa peran orang tua sangat penting untuk keberhasilan sekolah. Hal ini terutama berlaku pada tingkat sekolah dasar. Kepala sekolah melakukan langkah-langkah untuk memperbaiki proses komunikasi dengan orang tua siswa dengan cara: 1.) Mengembangkan program kemitraan dengan orang tua; 2.) Mendorong orang tua untuk ikut berpartisipasi pada tingkat kelas yang tidak ditempati oleh anakanak mereka; 3.) Menyiapkan konsep SWAP (Schools Wanting to Acknowledge Parents), orang tua dapat bertukar tempat dengan siswa untuk demonstrasi pelajaran; dan 4.) Mengembangkan dewan penasehat yang mendorong orang tua untuk mendiskusikan masalah dan memungkinkan orang tua untuk memberikan masukan pada program baru.

Fenomena hasil penelitian tersebut senada dengan teori Whitehead, Boschee, dan Decker (2013, p. 185) yang mengungkapkan bahwa keluarga (orang tua) memiliki pengaruh besar terhadap prestasi anak-anaknya, baik di sekolah maupun dalam kehidupannya. Ketika sekolah, keluarga dan komunitasnya bekerja sama untuk mendukung pembelajarannya, maka akan berdampak pada kecenderungan anak-anak untuk betah dan tinggal lebih lama di sekolah. Keterlibatan orang tua memungkinkan bagi anak-anaknya dalam mencapai nilai yang lebih tinggi dan meningkatkan minat mereka untuk melanjutkan pendidikan ke jenjang yang lebih atas. Keterlibatan orang tua juga berpengaruh terhadap kehadiran siswa di sekolah, siswa memiliki keterampilan sosial yang baik, berperilaku baik, dan mampu beradaptasi di sekolah, sehingga dimungkinkan siswa tersebut lulus dan melanjutkan pendidikannya ke jenjang yang lebih tinggi.

Lunenburg dan Irby (2006, p.357) menyatakan bahwa keterlibatan orang tua sangat penting dalam mengembankan rasa anak dari tanggung jawab pribadi kepada orang lain atau berperilaku etis. Kepala sekolah dapat memfasilitasi program keterlibatan keluarga yang fokus pada kerja dengan keluarga untuk menanamkan rasa tanggung jawab dan empati dalam setiap siswa. Hubungan sekolah dengan masyarakat yang baik akan memberikan kesadarana pada anggota masyarakat yang lebih besar tehadap tujuan dan prestasi sekolah. Bidang kerja sama antara sekolah dan orang tua yang diungkapkan oleh Suryosubroto (2000, p. 58) antara lain: bidang pendidikan mental, bidang pengembangan bakat, bidang pengajaran, bidang kebudayaan, dan memecahkan masalah orang tua dan siswa. Suatu program pendidikan akan berjalan dengan baik jika learning communitynya baik, hal tersebut dibuktikan oleh Hintz dan Genareo $(2017$, p. 9) dalam penelitiannya yang mengungkapkan bahwa:

Few descriptions exist of First Year Experience (FYE) learning communities specifically designed for education students, and no literature has yet explored Problem Based Learning $(P B L)$ as a means of student collaboration, relationship-building, and public demonstration of competence in FYE cohorts of such students. In this FYE case, we feel we are achieving what we set out to do: to expose our students to the authentic field of teaching, build relationships among faculty and students, and help retain the students who truly want to become teachers. We hope other education programs consider these suggestions, which have emerged from years of successes and challenges.

Penelitian Hintz dan Genareo didukung oleh penelitian yang dilakukan oleh Huerta yang menyatakan bahwa learning community sangat membantu dalam memajukan program pembelajaran, Huerta (2017, p. 3) menyatakan bahwa:

Learning communities have a long history in higher education with well documented benefits for students and faculty. The Washington Center at the Evergreen State College; the National Learning Communities Conference, state Consortia in California, Illinois, Washington, and 
Texas; and regional consortia representing the Atlantic Center for Learning Communities, South Atlantic Learning Communities Consortium, and the Great Plains Learning Community Consortium are among the organizations that have worked to advance learning communities.

Selain learning community, school partnership juga sangat berperan dalam memajukan sebuah program pendidikan. Bano, Anjum, Rahman, Sadia, dan Sarwar (2013, p. 1) dalam penelitiannya yang mengungkapkan bahwa:

Family involvement in school has been universally recognized as an essential component of students" success in all spheres of life. Students with special learning needs require more parental involvement regarding positive outcomes in many areas such as educational, behavioral, social, emotional, vocational, etc. This study aimed to investigate the perceptions of teachers and parents about the home school partnership in the context of special education.

Menurut pendapat orang tua siswa SDPN Sabang dan SDK 5 BPK Penabur kota Bandung bahwa Edmodo sangat mempermudah putera puteri mereka dalam belajar terutama dalam bidang IT, meningkatkan kemampuan IT putra putri mereka, hasil belajar semakin meningkat, dan smartphone yang biasa dibawa oleh putra putri mereka sekarang menjadi lebih bermanfaat untuk belajar. Komunikasi yang baik membantu kepala sekolah dan humas dalam menemukan kelemahan pada sistem. Whitehead, Boschee, dan Decker (2013, p. 315) menyatakan bahwa kepala sekolah harus dinamis dan kreatif dalam komunikasi dengan orang lain dan yang lebih penting, para pemimpin sekolah harus dapat menunjukkan tingkat keterlibatan yang tinggi dalam pekerjaan masyarakat, pengembangan profesional, pengawasan instruksional, dan perbaikan iklim. Selain itu, mereka harus secara pribadi berkomitmen untuk pendidikan, serta mampu berkomunikasi dengan masyarakat umum.

\section{Kendala dalam Pelaksanaan Program Edmodo}

Salah satu kendala awal pelaksanaan Edmodo adalah karena adanya hambatan orang tua yang mengkhawatirkan anak-anaknya dalam membuka dan memanfaatkan internet. Hal ini terjadi karena orang tua siswa pada saat Edmodo hadir, mereka belum siap dengan adanya perubahan dari kelas konvensional ke kelas digital. Lunenburg dan Irby (2006, p. 240) mengungkapkan bahwa terdapat kecenderungan manusia untuk menolak perubahan, karena dengan adanya perubahan tersebut seseorang harus mengadopsi cara-cara baru. Kepala sekolah harus memahami mengapa orang menolak perubahan. Berikut ini adalah beberapa alasan orang menolak perubahan menurut Lunenburg dan Irby (2006, p.240) yaitu: 1.) Adanya keraguan, guru mungkin menolak perubahan karena mereka khawatir tentang kerja dan kehidupan akan terpengaruh oleh perubahan yang diusulkan karena adanya potensi ketidakpastian; 2.) Kerugian pribadi, perubahan yang akan menguntungkan sekolah dimungkinkan bisa menimbulkan kerugian personal baik dalam hal kekuasaan, prestise, gaji, kualitas kerja, kewenangan pengambilan keputusan, akses ke informasi, dan otonomi ataupun karakteristik yang melekat pada pekerjaan; dan 3.) Adanya perlawanan kelompok, kelompok menetapkan norma atau aturan perilaku dan kinerja yang dikomunikaiskan dengan anggota disertai batasan-batasannya dan sanksi.

Jika kepala sekolah menetapkan perubahan norma atau aturan tanpa pemberitahuan dan persiapan terlebih dahulu ada kemungkinan adanya penolakan terhadap norma atau aturan tersebut, adanya ketergantungan karena manusia pada dasarnya diciptakan sebagai orang yang tergantung dengan orang lain. Namun, apabila ketergantugan ini bersifat ekstrim, maka akan menimbulkan penolakan terhadap perubahan. Hal ini terkait dengan tingkat kepercayaan terhadap kepala sekolah, jika perubahan diusulkan ketika kepercayaan rendah, reaksi pertama alami adalah untuk menolaknya, di sisi lain, ketika kepercayaan tinggi, guru lebih mungkin untuk mendukung perubahan yang diusulkan, serta kesadaran kelemahan dalam perubahan yang diusulkan. Guru mungkin menolak perubahan karena mereka menyadari potensi masalah dalam perubahan yang diusulkan. Jika guru mengungkapkan alasan mereka untuk bertahan dengan pembuktian yang memadai, bentuk penolakan perubahan dapat bermanfaat bagi sekolah. 


\section{Cara Mengatasi Kendala Pelaksanaan}

Adapun kendala diatasi dengan mengerahkan pihak-pihak yang terlibat. Hal tersebut didukung oleh teori Lunenburg dan Irby $(2006$, p. 245) bahwa kepala sekolah berperan sebagai pelatih dengan membantu staf sekolah belajar bagaimana menggunakan data untuk perubahan. Teori Lunenburg dan Irby didukung pula oleh Uno dan Mohamad (2013, p. 156) mengungkapkan bahwa upaya menjadi guru kreatif adalah dengan cara mendorong menjadi kreatif yang merupakan tuntutan profesionalisme. Oleh karena itu, tanggung jawab semua pihak dalam pembinaannya, terutama pemerintah, pemerintah daerah, guru serta komunitasnya. Instrumen-instrumen untuk mengoptimalisasi peran dan fungsi guru harus drancang dengan memperhatikan kepentingan guru berdasarkan nilai-nilai religi dan kearifan lokal serta mengacu pada kebutuhan peserta didik untuk mengembangkan potensi kompetensinya secara optimal.

Dari paparan Uno dan Mohamad (2013) tersebut, jelas bagi guru yang masih kurang dalam nilai inovasi dan kreativitasnya harus diberikan latihan. Khusus untuk penelitian manajemen program Edmodo ini, peneliti mengkhususkan pelatihan guru yang belum kreatif dan inovatif ke dalam pelatihan atau workshop mengenai program Edmodo. Guru yang belum bisa menggunakan komputer, dilatih untuk belajar mengoperasikan komputer dengan baik, guru yang sama sekali tidak tahu tentang apa itu aplikasi Edmodo diberikan pelatihan dari tim pengemabang Edmodo. Di samping diberikan pelatihan bagaimana cara mengakses Edmodo, menggunakan program Edmodo, guru-guru pun dilatih untuk membuat bahan ajar yang kreatif dan inovatif dalam kegiatan pelatihan ini. Kendala pelaksanaan Edmodo terkait sarana dan prsarana, Musfah (2015, p. 229) mengungkapkan bahwa pemerintah bertanggung jawab menyediakan sarana pedidikan yang memadai, baik di sekolah negeri maupun sekolah swasta. Di era ekonomi ini, pemerintah daerah seharusnya lebih berperan memenuhi sarana sekolah yang memadai terutama didaerah-daerah terdalam, terluar, dan terdepan. Pengusaha bisa mengarahkan dana sosialnya ke sekolah untuk melengkapi sarana yang kurang. Dana masyarakat, seperti zakat, infaq, dan sedekah bisa digunakan untuk sarana pendidikan. Pendidikan harus menjadi tanggung jawab dan perhatian bersama.

Kendala pelaksanaan Edmodo selanjutnya dikuatkan oleh Danim (2006, p. 108) para guru harus yakin dan menerima realitas bahwa mereka adalah kelompok pendorong bagi proses perubahan. Oleh karena itu, kesiapan mereka untuk menyumbang pada perubahan sangat penting. Beberapa strategi yang efektif diterapkan agar warga sekolah siap terlibat dalam pemecahan masalah secara sinergis di antaranya adalah: 1.) Mencari dan menentukan komunitas sekolah, terutama guru, yang mau menyediakan waktu dan energi untuk membahas masalah mereka dan masalah di lingkungan sekolahnya; 2.) Mencari guru-guru yang tidak pernah pesimis dan tidak pula menyerah begitu saja pada keadaan; 3.) Mencari guru dan staf yang dapat dimotivasi dengan satu pandangan pencapaian bersama dan saling pengertian; 4.) Kepala sekolah membangun kesadaran internal bahwa program-program pada masa lampau tidak membuahkan hasil yang baik dan karenanya perlu perumusan perencanaan ulang; 5.) Mencari siapa saja yang memahami bahwa sekolah adalah sistem yang kompleks dan norma dalam kelompok kerja adalah kunci produktivitas dan perubahan; 6.) Mencari siapa saja yang percaya bahwa pasti ada cara yang lebih baik untuk mengatasi kesulitan yang ada dan akan berhasil melampauinya; dan 6.) Mencari siapa saja yang mengetahui bahwa perkembangan sekolah akan membutuhkan energi ekstra dan bahwa perubahan akan membutuhkan keterampilan yang mereka tidak miliki, tetapi dapat dipelajari.

Jika kendala dalam Edmodo tersebut dikarenakan jaringan internet, Pujiriyanto (2012, p. 174) menyatakan bahwa untuk bisa mengakses internet diperlukan perangkat-perangkat sebagai berikut: 1.) Modem, modem adalah perangkat yang memungkinkan dua komputer atau lebih saling berkomunikasi melalui beragam tipe jalur komunikasi misalnya telepon kabel. Modem kepanjangan dari modular demodulator yang mengubah data digital menjadi analog (modulate) untuk dikirimkan melalui kabel telepon dan modem penerima mengubah data analog menjadi data digital kembali (demodulate). Terdapat 2 jenis modem, yaitu internal dan eksternal. Modem internal biasanya ada di dalam komputer (tertancap pada slot motherboard), sementara modem eksternal terpisah dari komputer dan terhubung dengan kabel telepon atau kabel LAN. Ada juga modem yang tidak menggunakan kabel telepon (wireless modem), bisa dibawa kemana pun dan dapat mengakses internet apabila terdeteksi adanya hotspot. Penggunaan modem yang disambungkan kabel telepon 
biasanya konesinya bersifat dial-up ke jaringan internet yang memerlukan software tertentu; 2.) Koneksi digital (DSL), tidak bersifat dial-up seperti pada modem, namun selalu menyediakan layanan transmisi data dalam kapasitas megabyte. DSL bisa dipakai untuk akses internet, pertukaran file, siaran televisi, video, telekomunikasi, pendidikan online, e-commerce, game online, dan telemedicine; 3.) Integrated Services Digital Network (ISDN), dirancang untuk menggantikan layanan telepon analog dengan layanan koneksi telepon digital berkecepatan tinggi $64 \mathrm{Kbps}$ sampai dengan $128 \mathrm{Kbps}$. Provider banyak mengembangkan teknologi ini sejak tahun 1990. Teknologi ini jarang digunakan untuk koneksi internet karena biayanya dihitung seperti pemanggilan telepon dan dalam durasi menit, sehingga terhitung mahal untuk melaksankan mengakses internet. Terdapat dua layanan internet ISDN yaitu BRI (Basic Rate Interface) memiliki dua saluran data yang bekerja $64 \mathrm{Kbps}$, bisa dikombinasikan sehingga mencapai $256 \mathrm{Kbps}$, dan PRI (Primary Rate Line) yang memiliki 23 saluran dengan kecepatan $1.544 \mathrm{Kbps}$; dan 4.) Layanan data satelit, layanan koneksi internet melalui satelit, komputer yang dapat terhubung melalui modem analog dan kecepatan yang ditawarkan cukup tinggi yaitu $400 \mathrm{Kbps}$ untuk aktivitas download. Beberapa provider penyedia jasa layanan satelit seperti Indosat, Iridium, Globalstar, Ellipso, Telestial, Roadpost, Thuraya, Mackay, Immarsat, Satellite Phones Direct, dan sebagainya.

Selain guru yang harus siap dengan perubahan, Lunenburg dan Irby (2006, p. 241) menyatakan bahwa kepala sekolah harus berperan aktif dalam melakukan perubahan dan mencoba untuk mengurangi penolakan untuk berubah. Kepala sekolah harus menilai potensi perubahan dan faktor penyebab penolakan dan kemudian berusaha untuk mengubah menjadi sebuah keseimbangan. Ada tiga cara pelaku dapat dilakukan yakni: 1.) Meningkatkan kekuatan pendorong; 2.) Mengurangi kekuatan yang menolak; dan 3.) Mempertimbangkan kekuatan pendorong baru. Ada enam pendekatan yang dapat dilakukan untuk mengatasi penolakan perubahan yang diungkapkan oleh Lunenburg dan Irby (2006, p. 242), yakni: 1.) Edukasi dan komunikasi; 2.) Partisipasi dan keterlibatan; 3.) Fasilitas dan dukungan; 4.) Negosiasi dan kesepakatan; 5.) Manipulasi dan co-optasi; dan 6.) Eksplisit dan implisit paksaan

\section{Kekhawatiran Internet Usia Sekolah Dasar dan Solusinya}

Kekhawatiran internet pada anak usia sekolah dasar didukung oleh teori Lunenburg dan Irby (2006, p. 244) yang menyebutkan tujuh tema dasar yang dapat dijadikan renungan saat akan mengadakan perubahan (dari kelas konvensional menjadi kelas digital Edmodo, yaitu: 1.) Perubahan adalah belajar; 2.) Perubahan adalah sebuah perjalanan, bukan blueprint; 3.) Masalah adalah teman kita; 4.) Perubahan adalah bersumber dari kekurangan; 5.) Perubahan membutuhkan kekuatan untuk mengelolanya; 6.) Mengubah sistematik; dan 7.) Semua perubahan skala besar dilaksanakan secara lokal. Kekhawatiran penggunaan Edmodo dari hasil penelitian tersebut harus berdasarkan pada asas kepercayaan seperti yang dungkapkan oleh Gibson, Donnely, dan Ivancevich (1997, p. 74) bahwa lebih banyak hasil yang bermanfaat bagi organisasi jika tingkat kepercayaan yang tinggi ada di antara kelompok yang terlibat dalam proses negosiasi.

\section{SIMPULAN}

Pelaksanaan program Edmodo adalah mengkaji dimensi siswa, guru, dan stakeholder yang terlibat dalam pelaksanaan program Edmodo. Adapun permasalahan dalam pelaksanaan Edmodo adalah: 1.) Hambatan mindset dan niat; 2.) Sinyal jaringan atau provider untuk mengakses internet; dan 3.) Sarana dan prasarana Edmdo yang belum lengkap di sekolah. Kendala terkini pelaksanaan di tahun ajaran 2016/2017 di Sekolah Dasar Percobaan Negeri (SDPN) Sabang dan Sekolah Dasar Kristen (SDK) 5 BPK Penabur kota Bandung adalah limitasi grup, yaitu kapasitas siswa yang dapat bergabung dalam satu grup tidak bisa melebihi dari 2.000 siswa. Cara mengatasi kendala dalam pelaksanaan Edmodo adalah 1.) Bekerja dengan ikhlas dan tetap semangat dalam melaksankan program Edmodo; 2.) Menentukan provider yang tepat ketika melaksanakan Edmodo bagi proses kegiatan belajar mengajar; dan 3.) Saling berkolaborasi dan bekerjasama antara sekolah dan orang tua siswa demi keberhasilan pelaksanaan program Edmodo, terutama dalam penyediaan fasilitas Edmodo. Dinas Pendidikan kota Bandung memantau penyebab kendala yang terjadi di lapangan. Jika kendalanya adalah infrastruktur, maka Dinas Pendidikan kota Bandung berusaha untuk 
membantunya, jika kendalanya berasal dari sumber daya guru-gurunya yang kurang, maka Dinas Pendidikan kota Bandung mengadakan pelatihan secara gratis untuk guru-guru tersebut.

Kegiatan pelaksanaan program Edmodo yang terlaksana dengan baik dan konsisten dapat berimplikasi pada peningkatan kemampuan ICT warga sekolah, prestasi siswa, guru dan sekolah dasar yang ada di kota Bandung. Agar siap mengahadapi era digital, guru-guru harus meningkatkan keterampilan dan kemampuan IT mereka dan memperkuat jaringan sesama guru baik di dalam kelas maupun di luar kelas. Pemberdayaan sumber daya manusia guru-guru melalui pelatihan ICT dan follow up evaluasi hasil kerja guru sebaiknya dilakukan untuk dijadikan acuan kebijakan mutu Dinas Pendidikan kota Bandung dan sekolah.

\section{DAFTAR PUSTAKA}

Bano, H., Anjum, N., Rahman, F., Sadia, T., \& Sarwar, N. (2013). Home-school partnership: A perspective of stakeholders in special education. Interdisciplinary Journal of Contemporary Research in Business, 5(7), 96-104. Retrieved from https://journalarchieves36.webs.com/96-104.pdf

Balasubramanian, K., Jaykumar, V., \& Fukey, L. N. (2014). A study on "Student preference towards the use of Edmodo as a learning platform to create responsible learning environment". Procedia-Social and Behavioral Sciences, 144(2014), 416-422. doi: https://doi.org/10.1016/j.sbspro.2014.07.311

Clark, R. C., \& Mayer, R. E. (2011). E-learning and the science of instruction. United States of America: Pfeiffer A Wiley Imprint.

Creswell, J. W. (2014). Research design fourth edition: Qualitative, quantitative, \& mixed method approaches. Boston: Pearson.

Danim, S. (2006). Visi baru manajemen sekolah. Jakarta: Bumi Aksara.

Darmawan, D. (2014). Inovasi pendidikan. Bandung: PT. Remaja Rosdakarya.

Dyches, T. T., Carter, N. J., \& Prater, M. A. (2012). A teacher's guide to communicating with parents. Boston: Pearson Educational, Inc.

Gibson, J. L., Donelly, J. H., \& Ivancevich, J. M. (1997). Manajemen edisi kesembilan. (S. Tjiptowardoyo \& I. Nurmawan, Trans.). Jakarta: Erlangga.

Hintz, K., \& Genareo, V. (2017). Suggestions for implementing first year experience learning communities in teacher education programs. Learning Communities Research and Practice, 5(1), 2. Retrieved from https://washingtoncenter.evergreen.edu/lcrpjournal/vol5/iss1/2

Huerta, J. C. (2017). The founding of the learning communities association. Learning Communities: Research \& Practice, 5(1), 7. Retrieved from https://files.eric.ed.gov/fulltext/EJ1150388.pdf

Kunandar, K. (2007). Guru profesional implementasi kurikulum tingkat satuan pendidikan (KTSP) dan sukses dalam seertifikasi guru. Jakarta: Raja Grafindo Persada.

Lunenburg, F. C., \& Irby, B. J. (2006). The principalship: Vision to action. USA: Wadsworth.

Mulyasa, E. (2015). Implementasi kurikulum 2013. Bandung: Remaja Rosdakarya.

Musfah, J. (2015). Manajemen pendidikan: Teori, kebijakan, dan praktik. Jakarta: Prenadamedia Group.

Pujiriyanto, P. (2012). Teknologi pengembangan media dan pembelajaran. Yogyakarta. UNY Press.

Rahma, A., \& Jonyanis, J. (2015). Pengaruh penggunaan smartphone terhadap aktifitas kehidupan siswa (Studi Kasus MAN 1 Rengat Barat). Jurnal Online Mahasiswa Fakultas Ilmu Sosial dan Ilmu Politik Universitas Riau, 2(2), 1-12. Retrieved from https://media.neliti.com/media/publications/32729-ID-pengaruh-penggunaan-smartphoneterhadap-aktifitas-kehidupan-siswa-studi-kasus-ma.pdf 
Pelaksanaan program Edmodo di sekolah dasar ... 107

Feni Febryani Zaman, Cepi Safruddin Abdul Jabar

Sugiyono, S. (2015). Metode penelitian pedidikan: Pendekatan kuantitatif, kualitatatif, dan R\&D. Bandung: Alfabeta.

Suryosubroto, S. (2000). Humas dalam dunia pendidikan. Yogyakarta: Mitra Gama Media.

Uno, H. B. \& Mohamad, N. (2013). Belajar dengan pendekatan paikem. Jakarta: Bumi Aksara.

Usman, H. (2013). Menjadi guru profesional. Bandung: PT. Remaja Rosdakarya.

Whitehead, B. M., Bosche, F., \& Decker, R. H. (2013). The principal: Leadership for a global society. Los Angles: Sage Publications, Inc.

Yin, R. K. (2009). Case study research: Design and methods. (4 ${ }^{\text {th }}$ ed.). California, Sage Inc. 